Understanding organizational culture to transform a workplace behavior: Evidence from a liberal arts University

Dr. Oris Guillaume

Assistant Professor and Chair of Graduate Business Programs

Shorter University, USA.

Dr. Amy Austin

Assistant Professor of Management, Dean of College of Adult and Professional Programs

Shorter University, USA.

(c) Scholedge International Journal of Management \& Development (2394-3378), Vol.03, Issue 04 (2016) pg89-96. Published by: Scholedge R\&D Center [http://journals.thescholedge.org/] [Email: editorial@thescholedge.org]

\begin{abstract}
Nelson and Quick (2013) describe organizational cultures as "a pattern of basic assumptions that are considered valid and that are taught to new members as a way to perceive, think and feel in the organization" (p.592). Organizational cultures are a vital part of any company's environment and provide employees with the necessary tools to integrate themselves into the overall organizational dynamic; however, most organizational cultures are plagued with dysfunctional dynamics that have stemmed from a dysfunctional personality of a key leader in their environment. This paper is based on the experience of designing and delivering special change, the organizational culture has been, for the most part, healthy and thriving. In this paper, we will review some of the problems facing the University and how key organizational leaders have successfully influenced change in a manner that has led to the valuable organizational culture in place today.
\end{abstract}

Key words: Organization Behavior, Transformation Changes, Service, Institution, Leadership.

\title{
Study Purpose
}

The most important thing in understanding the influences of a strong and functional culture is to determine what problems face an organization or industry and how leadership value enactment affects the institutional workforce. In recent years, collegiate enrollment has been trending upward for larger institutions, but trending downward for institutions with enrollment under 2500 students (Borden, 2011). This is especially true in private higher education institutions, such as this University, which (due to recent tuition trends and job scarcity) have led to a student culture steeped in student loan debt (Alkandari, 2014). Student graduation rates have also decreased significantly with the increase in debt (Alkandari, 2014). This has placed the private university system in jeopardy, specifically the liberal arts universities, and may "no longer attract students in anywhere near their historical levels" (Fein, 2014, p.200).

Therefore, many small universities have to enact extreme changes to maintain a competitive stance in a more capitalistic higher education market (Fein, 2014). The problem is that as these changes take effect, employees are faced with many difficult decisions in order to successfully maneuver the market place and remain successful, something that requires them fall back on the organizational culture to determine what behaviors are valued by the organization (Nelson \& Quick, 2013). Schein (2004) states that leaders manage culture by how they pay attention, react to crises, behave, allocate rewards, and hire/fire individuals; without these actions, chaos and dysfunction will ensue. 
he most common reason for this type of dysfunctional behavior is a culture built on the leadership example of being self-serving, rather than putting the needs of the organization or consumers first (Burch, Swails, \& Mills, 2015). Each of these examples, if not done in accordance with the established corporate values, create artifacts that are representative of a dysfunctional culture (Schein, 2004; Nelson \& Quick, 2013).

\section{Background of the problem}

One of the most significant issues for collegiate organizations is creating a strong organizational culture that is enacted by their employees who work together effectively and cohesively, specifically in times of transformational change. Colleges and universities, historically, have been extremely resistant to change and unresponsive in terms of leadership changes. This is often due to the unsuccessful or unresponsive nature of the relationship between leadership and faculty (Shugart, 2012). Dysfunctional managerial leadership is one of the key reasons for a dysfunctional culture within an origination, leading to poor employee engagement and job satisfaction (Leary, Green, Denson, Schoenfeld, Henley, \& Langford, 2013). Many higher education leaders have historically had problems remaining in the bounds of their own promoted values, such as the instance of the recent Penn State scandal. These leaders' actions directly modify the engagement of employees under their command and effect the assumptions of employees at every level, specifically faculty dealing with day to day issues directly linked to the institutions values and norms (Leary et al., 2013). Nelson (2012) said "The gates are emblazoned with mottoes: "ENTER TO LEARN" faces outward; "GO FORTH TO SERVE" faces inward. Even more than other liberal arts colleges, this university feels like a self-contained world - a campus upon a hill (para, 7).

\section{Methodology}

A qualitative study was conducted to explain Organizational Culture that innovate a workplace behavior: Evidence from a non-profit university. Garner (1971) Argued that this University has long been known as one of the leading liberal arts colleges in the Southeast and a strong environment of Christian values for its students, founded in 1873 , and has remained such a staple in the liberal arts community because of its dedication to its students and his organizational culture that represents his values mainly its values. The questions which grounded the qualitative study performed by Nelson (2012), were as follows:

1. What tradition is more powerful: faith values or academic freedom?

2. What defines Baptist values and what does it really mean to be a Christian University?

3. What is cultural change?

A qualitative study was conducted to analyze and understand organizational culture and value at the university. According to Taylor-Colbert (2015), the university is committed to "enabling and encouraging student commitment to active life-long learning, personal spiritual values, responsible citizenship, and community and societal leadership in a global context (para. ?)." She further explained that, after a corporate restructuring in April 2003, "the Georgia Baptist Convention no longer elects trustees for the selected university, but it remains committed to its Baptist heritage and to integrating Christian values within a nurturing community "(para, 6) as its mission states. 


\section{Theoretical Framework}

The iceberg analogy can explain the cultural awareness with the university. With that said, we have internal and external culture to exhibit here. Culture is not something which is always easy to understand. Culture includes a system of values particular to one that includes a system of values particular to one group not innate but imbibed, passed down from one generation to another generation. The Iceberg Analogy of Culture External and internal culture is values and thought patterns that explained the change at the selected University.

The iceberg analogy of Culture

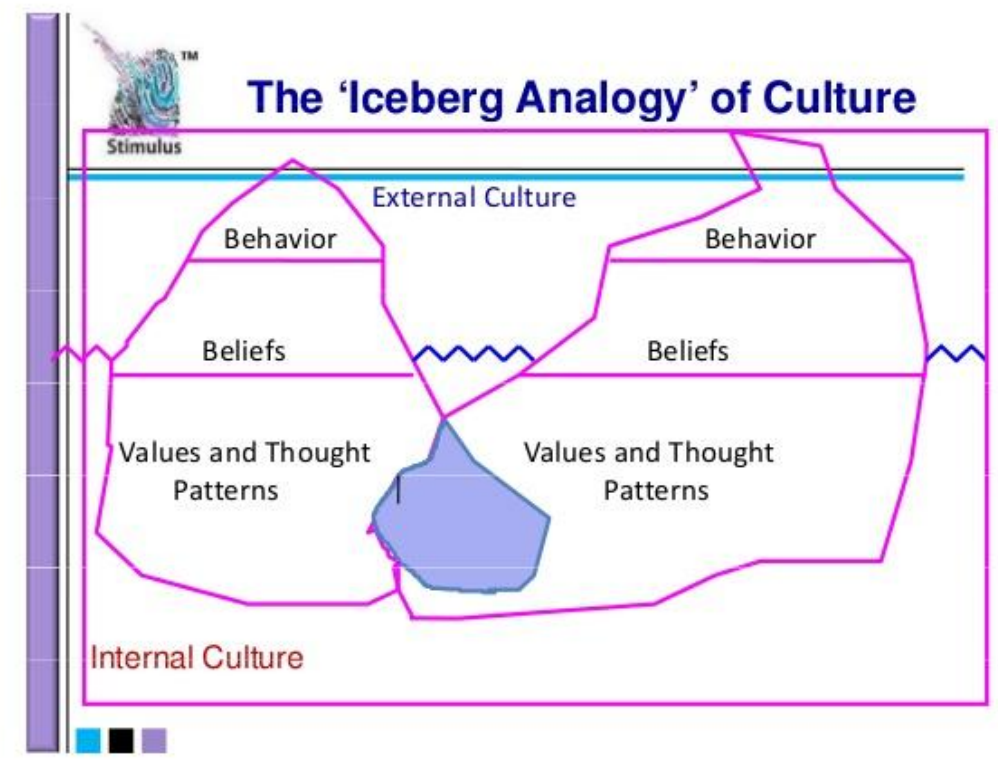

Source: Beyond Culture (1976) by Edward T. Hall

Hall (1976) developed the iceberg analogy of culture. If the culture of a society was the

iceberg, Hall (1976) further reasoned there are some aspects visible, above the water, but there is a larger portion hidden beneath the surface. This organizational culture was established within the university is represented through their new motto in 2010, "Transforming Lives Through Christ", and their established core values, which are being Christ-centered, excellence-focused, Biblically-based, and service- (para, 1). Nelson (2012) the college's motto had once been Lux et veritas - "light and truth," a well-worn Latin phrase they shared with Yale University. A year after the faith statements were introduced, current and former faculty still seem stunned and disbelieving when talking about the controversy that engulfed campus. The University has faced a decision-making which summarized and old saying, "To be or not to be?" That is a decision. Humanity has always lived in the 
shadow of fears with new changes. This model teaches us is that we cannot judge a new culture based only on what we see when we first enter it. We must take the time to get to know individuals from that culture and interact with them. Only by doing so can we uncover the values and beliefs that underlie the behavior of that society.

What has set this University apart from the competition is how the recent workforce has internalized these values and begun to express their Christian-values within their workplace, (both in their interaction with coworkers and students); the University's employees are unified namely by guiding their behavior through a shared sense of value (Howell, Kirk-Brown, \& Cooper, 2012). Its integration of values in the workplace are a perfect examples of enacted values, which are described by the recent authors as "values and norms actually converted into employee behavior" that work in "strengthening the organizational culture as well as serving as a source of identity" (p.734).

\section{Literature Review}

On many occasions when teaching, training, and leading discussion on intercultural topics, researchers have found that people often think of religion and culture as two separate entities, failing to realize that they are actually very much interlinked. If one looks at the definitions used to describe culture, it can viewed as being the traditions of a group of people, the shared values and beliefs of that group, and the behaviors which are seen as acceptable within it. Religion, just like culture, also consists of patterns of values, beliefs and behaviors followed by people practicing that religion (i.e. belonging to that group). In both religion and culture, the manifestations of these constituents occur regularly in their manner, are expressed in a number of ways, and are shared by a wide group of people.

For this institution, the fix for this issue was to hire leadership that represented the established Biblical values the school was modelled on and to hire individuals who would internalize the values more efficiently. In this case, the president of the university was brought on in 2011 to enact both a Biblical value model based on being a "service-oriented" institution that produced the faith and lifestyle statements. The trustees also approved another change with the adoption of a new motto that has branded on the banners amid the red-brick, white-columned buildings of its campus: "Transforming Lives Through Christ."

This principle, specifically, is one that has aided in the University's workforce cohesion. A recent article by Burch et al. (2015) discusses the historical success of Biblically based institutions, something that is largely due to the presence of a "transformational leader and servant leader models" (p.399). Servant leadership is defined as someone who is a "servant first" and has "emphasized personal development and empowerment of the followers" (Burch et al., 2015, p.400). True servant leaders are important because they display the values of the organization through personal enactment, providing stories and symbols for their employees to base their behavior on (Nelson \& Quick, 2013; Burch et al., 2015). On the other hand, Oshry (1995) suggests that when there is a break between how leaders perceive their enactment and how employees see them is when dysfunction begins, leading to lower morale, miscommunication, and loss of productivity.

While servant leadership can have weaknesses, specifically the aforementioned disconnection between leadership and employee perception, it has shown to be quite valuable in creating a culture that is committed to the organizational purpose, adheres to strong values, and remains optimistic in the face of struggle or change (Burch et al., 2015). This has definitely been the case at this University,

http://dx.doi.org/10.19085/journal.sijmd030401 
where the current staff and faculty have come together to grow the organization into new territories, such as online programs, despite budgetary constraints and somewhat stagnant enrollment. These types of strong cultures tend, on average, to perform at a much more productive rate that ones with weak or dysfunctional cultures (Nelson \& Quick, 2013).

\section{Proposed Organization Development Plan}

Nelson \& Quick (2013) describe this task by stating, “Changing an organization's culture is feasible but difficult. One reason for the difficulty is that assumptions - the deeper level of culture - are often unconscious" (p.609). These unconscious assumptions require significant effort to change or overwrite because the culture has been an individual's method of making sense of the organization and their environment (Ribando \& Evans, 2015). Dysfunctional cultures with leadership that either does not enact espoused values or intentionally promotes values in opposition to those held by the organization will be difficult to revert to correct path right away because employees are already behaving in a manner that is congruent with their understanding of the company (Ribando \& Evans, 2015).

Therefore, the first step toward creating a functional and efficient culture is to carefully evaluate the current organizational culture (Muratovic, 2013). Muratovic (2013) recommends first creating an organizational culture profile for both the existing culture and desired culture and then comparing the two to determine the missing enacted values or specific leadership mistakes to know what future steps to plan. This evaluation can easily be performed by using the technics of Cameron and Quinn and Kezar and Eckel, which label the four cultural categories as either clan (collegial), market (corporate), adhocracy (entrepreneurial), and hierarchy (bureaucratic) (Ribando \& Evans, 2015). Determining where an organizational culture falls on this scale will help determine what changes should be made to the cultural dynamic.

Taking the steps to changing this cultural dynamic also requires a leadership dedicated to enacting values to represent the desired culture (Ribando \& Evans, 2015). This can be done by ensuring that managers are demonstrating servant leadership characteristics through five specific means: changing organizational behavior, examining behavioral justifications, consistent cultural communication, hiring to reflect the new culture, and slowly reshaping the workforce to match the culture (Nelson \& Quick, 2013). These steps are extremely reminiscent of the steps taken to enact their current Christ-based culture. Nelson (2012) "We want people who measure up with high academic quality but also who love Jesus Christ," Nelson (2012) paraphrased the president at a news conference and said "We believe that we've been able to do that. We give the Lord credit for bringing the right people here at the right time" .

\section{Required Resources}

One of the most visible and useful tools in changing the organizational culture of an organization is to recreate or construct a clear and simple mission statement to relays that portrays the values that characterize the organization (Nelson \& Quick, 2013). This simple change will help symbolize the values of the organization's new culture and set a baseline for interpreting the organization's goals and strategies. This also provides a starting point for the organization to create cultural artifacts to communicate these values on a more personal, deep rooted level (Nelson \& Quick, 2013). 
Second, a strong leadership committed to the core values of the organization is required, as well as managers who are willing to work under a servant-leader model. These individuals must display leadership qualities that reinforce values through acting as a role model, teacher, coach, and authority figure in a way that internalizes these ideals (Nelson \& Quick, 2013; Burch et al., 2015). Leaders must also be open to feedback as the organization changes to react to future organizational changes and remain somewhat flexible to the needs of the institution while remaining static in terms of values (Burch et al., 2015). Leaders must also have a clear strategy for the type of personnel changes and restructuring changes needed to create this environment (Nelson \& Quick, 2013).

Last, leaders must have a concrete plan on shaping the behavior of the organization through a specific socialization and training process. Socialization, how newcomers are integrated into an organizational culture, are typical done in three stages: anticipatory socialization, encounter, and change and acquisition (Nelson \& Quick, 2015). Anticipatory socialization determines employee selection and fit with the culture based on expectations and values (Nelson \& Quick, 2013; Moldovan \& Macarie, 2014). Encounter is an employee's first reaction to his role at the organization through training and relationships, which are often molded through stripping away previous cultural characteristics and teaching of organizational values through practice (Nelson \& Quick, 2013; Moldovan \& Macarie, 2014). Last, change and acquisition is an employee's master of their job through rewards and subconscious entrenchment of organizational values (Nelson \& Quick, 2013; Moldovan \& Macarie, 2014).

\section{Timeline}

Changing an organizational culture and socializing new employees is an extremely gradual and long-term process. Moldovan and Macarie (2014) describe this as an evolutionary process, one that is done in three stages: "unfreezing, change, and refreezing" (p.42). This is a slow and deliberate action that requires a top-down approach (Nelson \& Quick, 2013). Effective organizational culture changes require leadership proactivity, alignment of structures and policies, ensuring participation, complex and consistent communication, feedback evaluation, and management of emotional and resistant responses (Moldovan \& Macarie, 2014). Each of these require exhaustive efforts to generate slow cultural transformations. Furthermore, unconscious assumptions require time and extreme effort. Nelson \& Quick (2013) describe this change, specifically employee changes, as a "lengthy process; it cannot be done effectively in a short period of time without considerable problems" (p.610).

\section{Anticipated Resistance}

What type of resistance should be anticipated in a complete organizational change? That largely depends on the level of change in which the organization is going through. After an organization determines, through extensive profiling, what types of changes need to be made, it should be fairly clear what types of resistance it faces. One of the most threatening aspects of organizational culture change is the integration of new organizational values and assumptions, as these are relatively unconscious beliefs that are deep rooted and are difficult to discuss, much less change (Nelson \& Quick, 2013). For example, this University faced a major shift in organizational values as it shifted from a fairly secular liberal arts environment to a Biblical, Christ-based institution. These changes initially sparked extreme resistance. This is where intentionality prior to change and long-term, gradual processes allow individuals who are willing to change the opportunity to be trained in new

http://dx.doi.org/10.19085/journal.sijmd030401 
values while more resistance individuals can slowly and less vocally be phased out (Nelson \& Quick, 2013).

\section{Need for Current Research}

The need for this research exists because the challenges that the university has faced throughout this transformational change changes. The potential benefits to strong organizational cultures are outstanding. The culture prior to this change was one riddled with dissected departments, lack of corporate communication, and rewards systems that promoted self-centered attitudes and selfish promotion rather that a culture serving students and the organizational goals (Nelson \& Quick, 2013). This research expands the body of knowledge to determine and validate if a correlation exists between the implementation of this new cultural change and transformation changes throughout Liberal Arts University then the researcher can further analyze the effect of the change which has opened up communication, increased efficiency, lowered turnover, provided greater cooperation between departments, and increased the level of positivity in an unprecedented way.

\section{Summary/Conclusions}

Overall, organizational cultures are extremely important to creating a cohesive and efficient workforce that is working toward a common corporate goal. Organizations that are facing dysfunctional culture are often plagued with a leadership dynamic that is out of tune with the organizations values and are creating cultural artifacts in direct opposition to the goals of the organization. Much like the example set by the change at this institution; positive and successful organizational culture changes require a strong leadership team who is both passionate and committed to the values they represent and the people for which the organizational culture will most likely effect, the employees. A servant-leader mentality, coupled with a specific cultural change and socialization plan, will aid universities looking to create a stronger culture in effectively moving their organization in the right direction with the least amount of resistance possible.

\section{References}

Alkandari, N. Y. (2014). Financial issues experienced by students in private higher education institutions. Education, 134(4), 465-474.

Borden, V. H. (2011). Slowing Down. Community College Week, 24(8), 7-11.

Burch, M. J., Swails, P., \& Mills, R. (2015). Perceptions of administrators' servant leadership qualities at a Christian university: A descriptive study. Education, 135(4), 399-404.

Fein, M. (2014). The 'Professionalized' Solution to the 'College Bubble'. Society, 51(3), 200. doi:10.1007/s12115-014-9766-1

Hall, E. T, (1976). Beyond Culture. Retrived from from the folks at www.constantforeigner.com

Howell, A., Kirk-Brown, A., \& Cooper, B. K. (2012). Does congruence between espoused and enacted organizational values predict affective commitment in Australian organizations?. International Journal Of Human Resource Management, 23(3), 731-747. doi:10.1080/09585192.2011.561251 
Leary, T. G., Green, R., Denson, K., Schoenfeld, G., Henley, T., \& Langford, H. (2013). The relationship among dysfunctional leadership dispositions, employee engagement, job satisfaction, and burnout. The Psychologist-Manager Journal, 16(2), 112-130. doi:10.1037/hoog4961

Moldovan, O., \& Macarie, F. C. (2014). How to change the informal side? A comparative analysis of organizational culture transformation models. Managerial Challenges Of The Contemporary Society, $7(2), 40-45$.

Muratović, H. (2013). Building competitive advantage of the company based on changing organizational culture. Economic Review: Journal Of Economics \& Business / Ekonomska Revija: Casopis Za Ekonomiju I Biznis, 11(1), 61-76.

Nelson, D. L. \& Quick, J. C. (2013). Organizational behavior: Science, the real world, and you. (8th ed.). Mason, $\mathrm{OH}$ : South-Western Cengage Learning.

Nelson, L.A. (2012). Shorter's Exodus, a Year Later, Retrieved from HigherED

Oshry, B. (1995). Seeing Systems. In Burch et al (Ed.). Perceptions of administrators' servant leadership qualities at a Christian university: A descriptive study. Education, 135(4), 399-404.

Schein, E. H. (2004). Organizational Culture and Leadership. San Francisco: Jossey-Bass.

Shugart, S. (2012). The Challenge to Deep Change. Planning For Higher Education, 41(1), 7-17.

Taylor-Colbert, (2015). "Shorter University." New Georgia Encyclopedia. 17 September 2014. Web. 25 September 2015.

Authors

1- Dr. Oris Guillaume, Assistant Professor and Chair of Graduate Business Programs at Shorter University - He earned a Doctorate in Business, a Law Degree, a Master in Leadership and Post-doctoral in Accountancy..

2- Dr. Amy Austin, Assistant Professor of Management, Dean of College of Adult and Professional Programs at Shorter University. - She earned a PhD in Management, A MBA, and a Postdoctoral in Accounting. 